\title{
Comment on: Nomenclature in Ventral Hernia Repair
}

\author{
Samuel G. Parker ${ }^{1}$ - Christopher P. J. Wood ${ }^{1}$ - David L. Sanders ${ }^{2}$ • \\ Alastair C. J. Windsor ${ }^{1}$
}

Published online: 13 November 2017

(C) Société Internationale de Chirurgie 2017

\section{Dear Sir,}

We read with interest Julie Holihan's and Mike Liang's reply [1] to our article on abdominal wall nomenclature [2]. Indeed, they highlight a couple of the difficulties involved in defining the planes of the abdominal wall and the fact that the colloquial terms "sublay" and "underlay" are open to subjective interpretation. Importantly, this article reiterates that no standardised nomenclature system exists.

We agree with the authors' initial statement concerning the term "onlay". Our definition does not include the rectus abdominis muscles, which often lie posterior to the mesh implant in this plane. Their definition of the "onlay" plane as pre-muscular is correct. Regarding the term "inlay", the authors are in agreement with our definition that the mesh implant is sutured to the edge of the hernia defect and acts as a bridge. When considering the terms "sublay" and "underlay", our institution does not agree with the definitions proposed in this response. In our article, we define two separate layers below the arcuate line; the "sublay" and the "underlay" planes, which are separated by the transversalis facia. Due to the confusion of the colloquial terms, we prefer to use the anatomical terms "retro-rectus" and "pre-peritoneal" instead of the terms "sublay" and "underlay" respectively, as the anatomical terms are less open to mis-interpretation. Above the arcuate line, these two planes are separated by the posterior rectus sheath. These principles are highlighted in our original article [2].

Samuel G. Parker

samgparker@nhs.net

1 The Abdominal Wall Unit, University College Hospital London, 235 Euston Road, London NW1 2BU, UK

2 Department of General and Upper GI Surgery, North Devon District Hospital, Raleigh Park, Barnstaple, Devon EX31 4JB, UK
Unlike the authors, we do advocate for the use of the term retro-rectus, provided a transversus abdominis release is not performed. If it is and dissection continues laterally, beyond the semilunar ligament, then we agree with the authors that the plane becomes "retro-muscular". Finally, with the term "underlay" in use as the pre-peritoneal plane this leaves only the two possible terms left for the deepest plane, either the intra-abdominal or intra-peritoneal plane. Mesh inserted into this plane in laparoscopic surgery; this is often called IPOM (i.e. intra-peritoneal onlay mesh).

We are pleased that our original article has stimulated such a debate in the surgical literature. With responses from the International Hernia Collaboration [3] and the University of Texas Health Science Centre [1], this is clearly an important issue that needs to be addressed. Since the publication of our article we have also been made aware of an additional plane through private correspondence. The ante-rectus plane, between the rectus-muscles and the anterior sheath, is used in some institutions for ventral hernia repair (Zorraquino, A, Abdominal Wall Department, Hospital de Basurto, Bilbao, Spain). An international classification system is warranted.

\section{References}

1. Holihan JL (2017) Nomenclature in ventral hernia repair. World J Surg. https://doi.org/10.1007/s00268-017-4301-3

2. Parker SG, Wood CPJ, Sanders DL, Windsor ACJ (2017) Nomenclature in abdominal wall hernias: is it time for consensus? World J Surg. https://doi.org/10.1007/s00268-017-4037-0

3. Muysoms F, Jacob B (2017) International hernia collaboration consensus on nomenclature of abdominal wall hernia repair. World J Surg. https://doi.org/10.1007/s00268-017-4115-3 